\title{
Cursussen, congressen en symposia
}

\section{Cursussen}

\section{PAOG}

Informatie over het PAOG-cursusaanbod in 2009 is te raadplegen via de website van de NVMO (www.nvmo.nl) en op de volgende websites:

- Wenckebach Instituut (UMCG): www.wenckebachinstituut.nl

- Boerhaave Commissie (LUMC): www.boerhaavenet.nl

- Nicolaes Tulip Instituut (AMC): www.amc.nl/congressen

- Erasmus MC - Het Congresbureau: www.hetcongresbureau.nl

- VU medisch centrum: www.paog.info

- PAOG Heyendael (UMC St Radboud): www.paogheyendael.nl

\section{PAOH (Julius Centrum UMC Utrecht)} Informatie over het $\mathrm{PAOH}$-cursusaanbod in 2009 is te raadplegen via de website www.paoh.nl

\section{Congressen en symposia}

Op het gebied van onderwijs vinden regelmatig symposia en congressen plaats. Hieronder een overzicht van interessante bijeenkomsten die binnenkort plaatsvinden:

\section{SHE}

11 november 2009, 13 januari 2010, 14 april 2010 en 29 september 2010

Vierdaagse cursus Onderzoek van Medisch Onderwijs met als start de preconference workshop van het NVMO-congres op 11 novemer 2009. Informatie 'School of Health Professions Education' (SHE): http://www.she.unimaas.nl

\section{NVMO-congres}

12-13 november 2009 (Egmond aan Zee) Informatie over het 19e NVMO-congres: http://www.nvmo.nl

\section{APMEC}

\section{4-8 februari 2010 (Singapore)}

Informatie over het 7e Asia Pacific Medical Education Conference (APMEC), met als thema 'Excellence in medical education quality healthcare': http://www/medicine. nus.edu.sg/meu/apmec7/

\section{Ottawacongres}

16-20 mei 2010 (Miami, USA)

Informatie over het 14e Ottawacongres, met als thema Assessment of Competence in medicine and the healthcare profession: http://www.ottawaconference.org

\section{ASPE}

27-30 juni 2010 (Baltimore, USA)

Informatie over het jaarlijkse congres van de 'Association of Standardized and Simulated Patient Educators' (ASPE): http://www.aspeducators.org 


\section{ASME}

21-23 juli 2010 (Cambridge,UK)

Informatie over het congres van de 'Association for the Study of Medical Education' (ASME): http://www.asme.org

\section{NVMO-congres}

11-12 november 2010 (Egmond aan Zee) Informatie over het 20e NVMO-congres: http://www.nvmo.nl

\section{AAMC}

5-10 november 2010 (Washington,USA) Informatie over het jaarlijkse congres van de 'Association for American Medical Colleges' (AAMC): $h t t p: / / w w w . a a m c . o r g / m e e t i n g s /$ future:htm

\section{NVMO-congres}

17-18 november 2011 (Egmond aan Zee)

Informatie over het 21e NVMO-congres:

http://www.nvmo.nl

\section{NVMO-congres}

15-16 november 2012 (Egmond aan Zee)

Informatie over het 22e NVMO-congres:

http://www.nvmo.nl 